\title{
The Implications of American Mathematics Graduates' Career Development on the Career Planning of Chinese Mathematics Graduates
}

\author{
Shuntao Zhang, Yiying Yang \\ School of Physics and Mathematics, North China Electric Power University, Beijing, 102206, \\ China
}

\begin{abstract}
This article starts with an careful analysis of the factors that cause Chinese mathematics graduate's heavy pressure in job hunting and career development, followed by a detailed introduction of American mathematics graduates' positive employment potential and their benign career development prospect. Finally the author puts forward that mathematics majors should plan their curriculum study in relation to their future career development, with the help of systematic, professional career development consultancy and guidance. Suggestions on how to improve mathematics majors employment competitiveness are also provided in this article.
\end{abstract}

Keywords. mathematics graduates; career development; implications

The higher education in China has been experiencing a giant progress in recent 30 years and in each year a growing number of university graduates are entering into the ever-crowded job market. According to the Ministry of Education, in 2014, the number of college graduates reaches a new peak with 749 million, an increase of 22 million compared with that of 2013. The fierce competition on graduate job market makes the employment rate a vital concern of families, universities and government. The backwash effect of graduate employment rate on college or university enrollment also reveal itself gradually, and even lead to more unbalanced development of "up" majors and "down" majors. Mathematics is a traditional major in most science and technology universities, and in recent years, it experience continuous depression in job hunting and career development. This article focuses on the career development of mathematics graduates, both in China and America, for purpose of penetrating the fog, finding solutions, and presenting the importance of systematic, professional career planning and guidance.

\section{The general picture of mathematics graduates' job seeking and career development in China}

In China, universities have various curriculum designs for mathematics majors, but in most universities, mathematics is regarded as an A-level discipline, made up of different subjects and branches. And most mathematics majors would take some common courses, like Mathematical Analysis, Advanced Algebra, Linear Algebra, Operations Research, Probability and Statistics, etc. And their future career development is more or less relevant to these curriculum courses. At the 
same time, the department of mathematics always played very important role for it could help build solid foundations for students from other science and technology majors. For example, students of computer engineering are expected to take certain mathematics courses to meet the prerequisite requirement when starting their advanced major courses. But what happened to the mathematics majors when they enter into the job market? Most of them face very severe pressure in finding a desirable job. To be a primary school or middle school Math teacher is one choice, not mention it is "good" or "bad". Besides that, a lot of graduates find no way out for even a math teacher's position is kept only for those math graduates who got degrees from professional normal universities (like East China Normal Universities or Central China Normal Universities). For those who hold a master's degree, their ambition to be an engineer or research fellow in a research institutions or universities has been denied more often than not. Therefore, some of them turn to other positions and compete with other science majors, but bear little or nearly no advantages. On the one hand, there are very limited chances for mathematics majors to do hands on operation for their academic courses are mostly pure theory-based, not practice-based. On the other hand, when turning to other directions, it seems very obvious that they are less competitive than other candidates, either in theoretical knowledge, or in practical skills. In China, except in some professional normal universities, mathematics is not a hot major, and a good proportion of mathematics students are forced into this major because they fail in their first application of other popular subjects. Therefore, they are struggling in a field that they do not know much about, and they have not any plan about "what to do" and "how to do", not mention any type of detailed occupation planning.

In one of the "Great Wall" projects of North China Electric Power University, researchers investigated the current employment rates of information and computing science graduates (one specialty in the department of mathematics), and they found that nearly half of the students choose to further their study either in China or abroad, only 13.2 percent of graduates got a position to work as a teacher or in the government (civil servant), and about 35.8 percent of them will go to businesses, industries and enterprises. The statistics looks very common but with indepth investigations, they found that most of their students choose jobs away from mathematics. The irony here is not rare in mathematics department of other universities. How to find effective ways to help mathematics graduate to plan career development, and how to help them to get a more brilliant career future, is a very realistic question.

\section{Various factors underlying the current pessimistic job market for mathematics graduates in China}

Firstly, for most mathematics graduates, the heavy pressure of job hunting is, on the first basis, the result of a structural contradiction: the contradiction between fast-developing human resources markets and lagging higher education.

Other factors are also surrounding this problem, including the transformation of the economic development structure, the imbalance of regional economic development, the inappropriate discipline allocation, and the out-of-date training mechanism. In one word, the current human resources development system, in a wide margin, lags behind the economic and social development.

Individual employment is not only affected by social factors, but also affected by psychological and personal factors. Most mathematics graduate take it for granted that they are doomed to be a primary or middle school teacher, which is a too narrow vision to limit their wider horizons. They are more reluctant to choose those "grass-roots" occupations, such as, to work in the poor villages or less developed cities. The great discrepancy between "what I want to be" and "what I could to be" makes the job seeking even more difficult.

As a basic pure theory discipline, mathematics is hard and demands learner great investment of time and effort if they want to be top students. Consequently, many mathematics scholarship winners have spent almost all of their college life in major courses, and are relevantly very limited 
in other campus activities or social work. What is worse, they are severely lack of support from other science subjects. They might excel in logical thinking, but relevantly weak in solving practical problems, and even not good at interpersonal relationships.

On the contrary, other mathematics students regard their own major of no use. They escape from the classroom and turn their eyes to other subjects. They learn English, computers, economics, philosophy, for purpose of enhancing their competitiveness. However, they go astray for only "know something about everything" is not a wise enough choice to deal with the everincreasing pressure from the job market. It is too late when they find they will graduate with some not so good certificates but know nothing about their own major.

\section{The salary and employers maps of mathematics career in America}

The employment chances of mathematics graduates are relevantly optimistic compared with that in China.

In 2008, there are a total of 2900 mathematicians in America. And in the coming years, the US job market demand for mathematics-related personnel will increase $22 \%$, with a $51 \%$ growth in promotion chances for math-related work. Mathematics graduates could be engaged in the wide range of work, including actuaries, statisticians and high school teachers. The median of average annual income for mathematics-related employees is $\$ 93,600$. In 2008 , the median of average annual salary of American mathematicians is $\$ 65,150$. For those mathematicians who get the minimal annual income in the whole group, $10 \%$ of them have an average income of $\$ 53,570$; for those middle mathematicians (50\% of the whole group), their annual salary ranges from 71,430 to 119,150 US dollars; for those mathematicians who get maximum annual income in the whole group, $10 \%$ of them have an average income above 140,500 US dollars.

In year 2009, the United States has a total of 14,550 actuaries, and their average annual salary is 87,040 , and among which $10 \%$ of the lowest income groups has an average annual salary of $\$ 42,250$, and 54090 US dollars for the $25 \%$ of the same group. In the middle actuary group, $50 \%$ of them get an average annual salary of 75,280 US dollars; in the top group, $25 \%$ of them get an average annual salary of 106820 US dollars.

In year 2009, the United States has a total of 21370 statisticians, and their average annual salary is 75,220 US dollars, and among which $10 \%$ of the lowest income groups has an average annual salary of 38,420 US dollars, and 50590 US dollars for the $25 \%$ of the same group. In the middle statistician group, $50 \%$ of them get an average annual salary of 72,820 US dollars; in the top group, $25 \%$ of them get an average annual salary of 95740 US dollars, and $10 \%$ of them get an average annual salary of 117210 US dollars.

In America, the career development of a mathematician is wide and flexible. Some mathematicians go the education route, and hiring demand for mathematicians is also very high among corporations, government agencies and the non-profit world. To quote Sobanski, a woman mathematician, "Conversion rate optimization: everything going on in that space is huge. Whether it's new product sales, a start-up (business model) or an established TV station, everything is based on numbers." Companies contract mathematicians who can spot these trends and increase more lucrative possibilities. Indeed, the US Bureau of Labor Statistics (BLS) estimates that in 2013, the median annual pay scale for mathematicians was $\$ 101,360$. And at a projected growth rate of $23 \%$ by 2022, the field's outlook is bright.

However, in an interview posted on MathsCareers home page, when people are asked "What career can a mathematics degree lead you to?", the responses, as the editor emphasizes, highlights that "there are very few jobs titled 'Mathematician'." As it says, the mathematics degree can open the door to a wide range of exciting careers, not just in finance, banking and teaching, as the skills gained from a mathematics degree are highly sought after in many different areas of employment. The collection of career profiles on the MathsCareers website highlights the fact that there is no 'typical job' for a mathematics graduate. 
In America, mathematics graduates, with adequate employability skills, are in high demand by employers. A mathematics degree offers a huge variety of career opportunities. Careercast.com lists possible career choices for mathematics graduates on its website:

Accountancy \& Profession
The Actuarial Profession
Computing \& IT
Engineering Sciences
General Management
Operational research
consultancy
insurance
intelligence and analysis
quantitative trading
design and development
statistical analysis
teaching

As indicated above, the job opportunities for mathematic degree holders are very huge in America, then what kind of skills they should have? Careercast.com also lists some skills to help, they are:

\section{logical and quantitative thinking \\ numeracy \\ ability to handle tricky intellectual challenges \\ problem solving skills \\ statistical inference}

Careercast.com also lists plenty of famous people who have taken their mathematics degrees in other directions. For example:

\section{Matt Groening \\ Bram Stoker \\ John Maynard Keynes \\ Art Garfunkel \\ Lewis Carroll}

Most important, this profession career planning company has designed many career planning tools for users to find out which career is most suitable to them. This website presents a "guide service", to help graduates navigate through the maze of career options. Each of the web pages offer an insight into relevant careers for mathematics graduates, including a description of career, the skills required, the pros and cons, as well as other useful links. For example, if the user clicks any key word, he/she will read some words like this:

Got a passion for business? A career in accountancy and professional service is a fantastic way of using the skills you've picked up during your degree. The industry is huge, offering variety and great career prospects. Click below to find out more.

Professional career planning service like this is very convenient and helpful, and can greatly enhance graduates' chance of locking a good position.

\section{The implications of American experiences to Chinese mathematics graduate career planning}

\subsection{To construct professional and systematic whole process career planning service system}

When comparing the Chinese and American mathematics career prospects, most career development advisers will agree on the construction of a professional, systematic and whole 
process career planning service system, to help change the current pessimistic job seeking plight. This professional team could be made up by professional career development facilitators, occupation planners, experienced professors, prestigious alumni and advisors from businesses or industries. It is expected to be highly professional, with its set work goals, professional websites, smart platforms, regularized schedule and relevantly permanent employees. It is expected to provide all around guiding service for mathematics majors, from the first day of a freshman to the end of their graduation. It is expected to have highly qualified staff who can deal with all problems, from "how to choose an optional course to "when to send my resume". It is expected to deal with a lot of tasks.

From American experiences, we know that a mathematic degree is very powerful in locking a good position if the candidates could make the best use of it. Therefore, the first task for this career planning center is to let students know their major and their future. In their website, they are expected to list potential job domain for candidates, with analysis of both pros and cons of each field, and what qualifications are demanded. With objective analysis and scientific planning, their work would greatly enhance student's confidence. They will know "what to prepare" and "how to prepare", and "what they can expect" and "what they can not". They will never be blind about their future, whether it is bright or gloomy.

Secondly, this career planning center should make clear plan to hold various seminars, lectures, competitions, workshops, to maximize the communication channels for mathematical majors, to let them know "what happened" and "what will happen". The invited guests could be prestigious alumni, or managers from partner businesses or industries, to keep a long term benign relationship with potential employers. On the one hand, businesses and enterprises could keep the established good reputation; on the other hand, students could get the clearest understanding of what is expected from them by their future employers.

Professional guidance should be integrated with conventional classroom, another important task for the career planning center. The center should grasp latest information from the job market, and provide constructive suggestions for thinking training, teaching methods, curriculum design and discipline development. In one word, it is expected to help students know "what are the game rules" and "who are the game changers".

Individualized and professional career planning would be a conventional work load of this center, with paper and digital graduate profiles, and all-level assessments from teachers and advisers. It is expected to provide reasonable career advices based on graduate's personality, qualification, internship or work experience, career expectation and salary expectation. It is also expected to help adjust graduate's career goals and career expectations, in relation to their learning and working experience. It could be as smart as reminding its users of "what's your next work", a small step of a whole process career planning service. Inspection and evaluation on the whole employment guidance model should also be the domain of this professional career planning center, including professional assessments, careful examinations, feedbacks and constructive suggestions.

\subsection{To adopt flexible mathematics curriculum in light of market needs}

Scientific curriculum design is the prerequisite requirements of successful career development in the future. The curriculum reform of college should keep pace with the market needs, also concerning the healthy future development of this discipline. The department of mathematics could open some cross-discipline subjects, or applied mathematics, to increase the competitiveness of its graduates. For those non-normal mathematics majors, they are expected to establish solid foundation in mathematic abilities through conventional courses (Mathematics, Mathematical Analysis, Linear Algebra, Probability and Statistics etc.), combined with popular courses including economics, finance, insurance, actuarial, securities, statistics and etc.

The mathematical modeling competition is a good way to start cultivate student's problem solving skills. As a survey in Careercast.com indicates, problem solving skill is very crucial to any mathematical degree holders. Field trips or internships, which have long been popular in 
technology majors, should also be added into the curriculum of mathematics majors. Students should be given chances to be in businesses, schools, government to get the latest information, to know the market needs, the salary span, the threshold requirements of highly-paid jobs, and what certificates they should prepare in college career. The key is to make learning and market always closely related, and learning is far from being blind.

\subsection{To give graduates more trainings and enhance their mathematical abilities}

Previous experience shows that in college students' job seeking, interviewers will always check if the candidates have good logical and quantitative thinking ability. In dealing with complicated mathematical problems, logical and quantitative thinking could quickly break the blocks and help find the right way to the solution. The training of logical and quantitative thinking is a long way, with days and days accumulation and hard work. When teachers conduct trainings, he/she should lead students to start from mathematical knowledge and gradually into mathematical thinking. Open question is a good choice to help exercise student's critical reasoning and thinking, with leap from surface learning to deep learning. Teachers can also design interesting games in his training, to attract more students to be in the training, and help relax the trainees.

Problem-solving ability is also crucial in help increase the lot of finding a good job. It could come from mathematical modeling competition, field trips or internships, and also from research projects. In China, most universities provide very decent funds to encourage student's academic research. It is highly recommended that the department could encourage students build their own research teams, or join in teacher's project research teams, to increase their problem solving abilities in innovation and creation.

\section{Suggestions for individual mathematics graduate in job-seeking}

Career planning is not a hard activity if candidates could make the best use of resources around them. Schools and universities have already provided scientific and systematic guidance, but skills in job-seeking also count to help individual to get a new start point. Here are some suggestions for mathematic graduates.

- $\quad$ Make career planning an long term event

- $\quad$ Map the career path since first year of the mathematics study

- $\quad$ Reflect on likes and dislikes, needs and wants

- Examine pastimes and hobbies

- Make note of the qualifications and certificates

- Look beyond the current major for transferable skills

- Review career and job trends

- Set career and job goals

- Explore training opportunities

Mathematics, a traditional yet new basic discipline, has been in refreshing air in continuous reforms and evolutions. Encouraged by the bright prospects of American mathematicians, statisticians, and actuaries, Chinese mathematics graduates could be more confident in their future career development, although they still have a long way to go. For mathematics institutions or colleges, updating teaching modes and optimizing curriculum to meet the needs of current job market has always been a wise decision. At the same time, the training and cultivating of student's logical and quantitative thinking is also on the top of the schedule, with their innovation and hands on creation experiences. The more urgent work for most mathematical institutions and colleges is to construct a scientific, systematic whole process career planning service center, to lead students through every crucial transition of their career development. Job seeking is market-oriented, more future-oriented, with improved qualifications and competence. 


\section{Acknowledgement}

This work is supported by North China Electric Power University "Great Wall” Project to Shuntao Zhang.

\section{References}

1. Chen Guohua. The exploration of career planning models for mathematics and applied mathematics majors [J]. Chinese \& Foreign Entrepreneurs. 2010(08).

2. Fang Bin, Li Yan, A study of career guiding models for mathematics majors [J]. Science \& Technology Vision. 2014(4).

3. Mathematics career advice. Institute of mathematics and its applications. 2011(3).

4. Sun Shanhui, Lu Wei. The career-oriented innovation cultivation models for mathematics undergraduates [J].Journal of Suzhou College. 2012(11).

5. Tang Xiaojing. A study of talent cultivation models of information and computing majors [J].University Mathematics. 2007(1).

6. Wang Yan. The problems of and solutions to mathematical graduates' job-seeking maze [J]. China University Students Career Guide. 2013(10).

7. http://www.careercast.com/jobs-rated/best-jobs-2014

8. http://www.southampton.ac.uk/maths/undergraduate/careers/career_opportunities.page 